\title{
Hepatocyte transplantation in children with liver cell failure
}

Mohamed Hamooda

MRCPCH, Paediatrics Specialty Registrar, West Yorkshire and the Humber, United Kingdom

Type of article: Review

\begin{abstract}
Patients with hepatic failure and liver-based metabolic disorders require management which is both costly and complex. Hepatocyte transplantation has been very encouraging as an alternative to organ transplantation for liver disease treatment, and studies in rodents, show that transplants involving isolated liver cells can reverse hepatic failure, and correct various metabolic deficiencies of the liver. This 2016 review is based on a literature search using PubMed including original articles, reviews, cases and clinical guidelines. The search terms were "hepatocyte transplantation", "liver transplantation", "liver cell failure", "metabolic liver disorders", "orthotropic liver transplantation", "hepatocytes" and "stem cell transplantation". The goal of this review is to summarize the significance of hepatocyte transplantation, the sources of hepatocytes and the barriers of hepatocyte transplantation using a detailed review of literature. Our review shows that treatment of patients with liver disease by hepatocyte transplantation has expanded exponentially, especially for patients suffering from liver-based metabolic disorders. Once hepatocyte transplantation has been shown to effectively replace organ transplantation for a portion of patients with life-threatening liver metabolic diseases and those with liver failure it will make cell therapy effective and available for a broad population of patients with liver disorders.

Keywords: Hepatocyte transplantation, Liver cell failure, Metabolic liver disease
\end{abstract}

\section{Introduction and methods}

Deteriorating liver function engenders considerable metabolic instability and complications to essential functions such as thermoregulation and acid-base balance leading to acute liver failure (ALF) (1). Presently the only treatment that improves the survival rate in patients with ALF is orthotopic liver transplantation (OLTx). Numerous immunosuppressive agents have increased the success rate of this procedure by rejection prevention. However, the unavailability of donor organs continues to be a major disadvantage. Hepatocyte transplantation has been attempted in order to provide a short term liver support until the suitable organ availability (2). This review was conducted in 2016 on PubMed. We included original articles, reviews, case reports and clinical guidelines. The search terms were "hepatocyte transplantation", "liver transplantation", "liver cell failure", "metabolic liver disorders", "orthotropic liver transplantation", "hepatocytes" and "stem cell transplantation". The goal of this review is to summarize the significance of hepatocyte transplantation, the sources of hepatocytes and the barriers of hepatocyte transplantation using a detailed review of literature.

\section{Sources of hepatocytes}

\subsection{Hepatocyte progenitor cells}

Two progenitor cell candidates have been successfully isolated in adult liver: Initially, oval cells were observed a few decades ago particularly at the very early stages of liver carcinogenesis induced chemically (3). Currently, such procedure is a frequently used model for oval cell proliferation induction (4). Oval cells indicated a great success in diseased liver cells replacement, as confirmed by transplantation into the livers of fumarylacetoacetate hydrolase deficient mice. Following transplantation, oval cells were able to repopulate the diseased liver and they were shown to be as effective as mature hepatocytes in liver regeneration (5). Oval cell induction guidelines have also displayed

\section{Corresponding author:}

Mohamed Hamooda, Paediatrics Specialty Registrar, West Yorkshire and the Humber, United Kingdom.

Tel: +44.7517609444, Email: dr.mohfawzi@yahoo.com

Received: April 04, 2016, Accepted: September 07, 2016, Published: October 2016

iThenticate screening: September 07, 2016, English editing: September 21, 2016, Quality control: October 01, 2016

(C) 2016 The Authors. This is an open access article under the terms of the Creative Commons Attribution-NonCommercialNoDerivs License, which permits use and distribution in any medium, provided the original work is properly cited, the use is non-commercial and no modifications or adaptations are made. 
they can differentiate into biliary and hepatocytic cells, indicating characteristics of bipotential oval cells (6). Other indications for oval cells bipotential properties can be given by in vitro studies in which permanent cell lines with oval cell-like protein expression patterns were identified (7). Also, experiments with bone marrow transplantation are evidence that oval cells could migrate into damaged liver (8).

\subsection{Bone Marrow Derived Stem Cells}

It is confirmed that adult non-hepatic stem cells, can differentiate into hepatocytic precursor cells. So, Petersen and associates highlighted that after bone marrow transplantation in rats, hepatocytes were shown in the liver which originated from the donor bone marrow cells (8). This was achieved by bone marrow cells transplantation from normal male rats into dipeptidyl peptidase IV deficient female recipient animals $(9,10)$. However, newer research indicated that the hepatocytes originating from donor bone marrow derived stem cells were actually had emerged by cell fusion (11).

\section{Significance of hepatocyte transplantation}

\subsection{Hepatocyte transplantation in experimental models with acute liver failure}

Hepatocyte transplantation efficacy has been analyzed in various animal models with acute liver failure (ALF). The most typically used models include thioacetamide-induced liver failure in rats and rabbits and in galactosamine induced liver failure in dogs, guinea pigs, rabbits and rats. In these studies, hepatocyte transplantation has displayed survival rates of more than sixty percent. Sixty million cells per kilogram body weight have been transplanted in Dgalactosamine-induced acute liver failure animal models with more than sixty percent rate of survival in treated animals' models compared to no survival in untreated controls (12).

\subsection{Hepatocyte transplantation in patients with liver failure}

Established from the pre-clinical data, clinical trials were initiated at various centers. In a trial of cirrhotic patients with hepatocyte transplantation, Hepatocytes were isolated from the cirrhotic livers segments, and transplanted by injection into the portal vein, splenic pulp, splenic artery or splenic vein. Although the injections were well tolerated, some indication of progress in protein synthesis, encephalopathy, and renal function, the eventual clinical result was not significantly altered. This study was an indicator for introducing hepatocyte transplantation into clinics (1). In an additional study, seven patients with acute liver failure were intraperitoneally infused with human fetal hepatocytes. Syngeneic hepatocyte transplantation has been practiced in ALF human patients using human fetal derived hepatocytes. Seven ALF patients of less than two weeks duration who had hepatic encephalopathy grades III or IV without complicating systemic illnesses, underwent hepatocyte transplantation; the initial results indicated that hepatocyte transplantation may be beneficial in ALF patients in grade III or IV encephalopathy. Such effects could be linked to their detoxification and metabolic function. Additionally, the transplanted hepatocytes may spread under the hepatotropic factors effect, thereby elevating their total detoxifying and metabolic capabilities (1). Successful bridging of patients to orthotopic liver transplantation through hepatocyte transplantation was reported in yet another study. Three of the five patients in the study were experiencing acute deterioration of chronic liver failure. Three patients were treated by infusing the hepatocytes through portal vein. Only one of the three patients responded to the therapy (13). In another study, intraperitoneal hepatocyte transplantation was carried out on the acute fatty liver of a pregnant twenty-six year old patient who recovered within two days of transplantation (14).

\subsection{Hepatocyte transplantation in metabolic diseases}

Hepatocyte transplantation into the liver corrected deficiency. A five year old child with ornithine transcarbamylase deficiency, urea cycle defect, received one billion hepatocytes and showed improvement clinically (15). In another study, a four year old child with infantile refsum disease received hepatocyte transplantation, which led to abnormal bile acids partial clearance with pipecholic acid reduction to $60 \%$ of pre-transplantation levels. The child was able to stand and walk within six months following hepatocyte transplantation (16). In another study, three patients with metabolic defects of liver function had been treated with hepatocyte transplantation. The first patient received one billion hepatocytes and showed improvement clinically, but 42 days after cell transplantation, he died of pneumonia. The second patient was given a hepatocyte transplantation and eventually received an orthotopic liver transplantation. The third patient was transplanted with seven point five billion cells (five percent of hepatic mass) through three infusions percutaneously placed into a portal vein catheter. The child continued to recover eighteen months after hepatocyte transplantation (17). 


\section{Barriers of hepatocyte transplantation}

Despite clinical trials of hepatocyte transplantation revealing the long-term safety of the procedure, only partial correction of metabolic disorders has been achieved. Although hepatocyte transplantation can be carried out safely in humans, its applicability remains restricted by a number of concerns (19).

\subsection{The challenge of treating acute liver failure}

There are many issues which have affected progress of innovative therapies for treating fulminant liver failure patients (20). The severity of liver dysfunction involves instantaneous function of the transplanted hepatocytes, however, with no clinically relevant disease model (21). The unpredictable nature and the various causes of acute liver failure have also made difficult the assessment of the success rate of novel interventions. So none of these procedures have managed to bring about reversal of hepatic failure to the point where organ transplantation can be avoided (22). Regarding hepatocyte transplantation, interpretation of its capacity has been influenced by the variety of types and numbers of the transplanted cells (23).

\subsection{The challenge of treating chronic liver disease resulting from cirrhosis}

Hepatocyte transplantation for end-stage liver disease is more demanding, because with hepatic architecture abnormalities there can be a risk of reduction in liver function, and transplantation of hepatocytes into the cirrhotic liver portal vein brings a risk of marked portal hypertension (24). Animal studies reveal that transplantation of decompensated liver cirrhosis into the spleens of rats can enhance liver function, and extend survival (25). However, transplanted hepatocytes supplied only transient function (14). It has been proven that the route of hepatocyte installation into the spleen can considerably affect hepatocyte engraftment and function (26). A new technology called organ de-cellularization, where the donor organ cells are removed, leaves the complex combination of structural and functional proteins that account for the ECM, intact. A de-cellularized human or animal liver could function as a biologic, architecturally normal scaffold for transplanted cells (27). The scaffold, repopulated with donor hepatocytes and non-parenchymal cells, could then, through the portal circulation, be vascularized (28).

\subsection{The challenge of hepatocyte engraftment and treatment of liver metabolic disorders}

In native normal and in immune deficient hosts, transplanted hepatocytes seem to poorly survive in the long-term (29). They are, however, able to survive well in patients with particular types of liver disease (30), and when native liver cell expansion is impeded by exogenous interventions (31). This is also evident in allogeneic bone marrow transplantation, in which the host is required to go through a preparative regimen to engender an environment supportive to long-term engraftment. Apoptosis of host bone marrow cells allows macrochimerism to occur following donor hematopoietic stem cells infusion (32). Consequently, unless conditions can be established that will allow the undergoing hepatocyte transplants survival, the use of hepatocytes for liver metabolic disease treatment may inevitably fail, as observed in various types of liver injuries. It has been proven that liver-directed radiation aids repopulation of the native liver by transplanted hepatocytes, particularly when combined with a hepatic proliferation stimulus (33). Indeed, supplying only the hepatic proliferation stimulus generally results in mild enhancement of hepatocyte engraftment for as long as sixteen weeks in non-human primates $(34,35)$. Host hepatocyte proliferation is usually suppressed by liver-directed radiation-based preparative regimens and promotes post-mitotic hepatocyte death (36). This strategy has been employed to fully correct rodent models of hereditary metabolic deficiencies of the liver corresponding to primary hyperoxaluria and Crigler- Najjar syndrome (37).

\subsection{The shortage of human donors}

The lack of human hepatocytes source has brought considerable restriction to the clinical application of hepatocyte transplantation. Hepatocytes are primarily acquired from livers incompatible to orthotopic liver transplantation, and unused parts of donor livers used for paediatric recipients. But, sources do not meet the potential numbers required to treat all patients who could benefit from hepatocyte transplantation (38). A recent study reported that these livers, of unknown quality for whole liver transplantation, could generate acceptable viable quality hepatocytes (39). The main restriction to incorporating these whole organs is the danger of possible long-term vascular and biliary complications. A number of children suffering from urea cycle disorders have been treated with a little success using cryopreserved hepatocytes $(40,41)$. Hepatocytes may also be acquired by growth and differentiation of stem cells (42). To achieve large numbers is challenging, and there is still the obvious risk of contaminating the enriched population with potentially tumor forming cells. Ideally, the source of stem cells would be derived from the subject to be treated (43). However, a period of many weeks is required to generate the adequate amount of functional hepatocytes for treatment of liver failure from autologous cells derived from iPS cells, essentially for selection, expansion, differentiation and testing to exclude contamination by tumorogenic precursors. Additionally, autologous 
hepatocytes would necessitate genetic manipulation in order to treat a metabolic disease and such manipulation could increase the risk of cancer. Thus, numerous unresolved problems make this source of hepatocytes questionable in the use of clinical transplantation in the near future. Finally, many of the challenges of treating liver diseases could be addressed by xenotransplantation of hepatocytes (44). Hepatocyte xenotransplantation has also been carried out with some success in small animals suffering from hypercholesterolemia (45). Furthermore, it has been shown that porcine hepatocytes produce albumin for months in native non-human primates $(29,46)$. Hepatocyte xenograft transplanted rats had improved coagulation parameters, less encephalopathy and survived longer than cirrhotic rats which did not receive hepatocyte xenografts (25). The porcine hepatocytes engrafted and corrected liver failure for approximately two months without the requirement of immune suppression. The hepatocyte xenografts caused sensitisation for the rodent recipients in liver failure. However, already engrafted cells were unharmed by the immune response. So, requirements for suppressing the immune system after hepatocyte transplantation in paediatric liver failure could be exceptionally low (47).

\section{Conclusions}

The treatment of liver disease in children, by hepatocyte transplantation has dramatically increased throughout the last ten years, particularly for treatment of liver based metabolic disorders. Considerable progress has been made, however, full realization of its capability has not been attained, and treatment of acute liver failure has been restricted by numerous factors. The obstacles to treating chronic liver failure due to cirrhosis are more extensive. Hepatocyte transplantation can be proven to successfully replace organ transplantation for a number of patients with liver failure and life-threatening liver metabolic diseases.

\section{Acknowledgments:}

There is nothing to acknowledge.

\section{Conflict of Interest:}

There is no conflict of interest to be declared.

\section{References:}

1) Khan AA, Parveen N, Habeeb MA, Paspala S, Rajendraprasad A, Mahaboob Vali S, et al. Cell Therapy for Acute Liver Failure - Ideal source of cell. J Stem Cells Regen Med. 2008; 4(1): 2-8. PMID: 24693024, PMCID: PMC3908132.

2) Khan AA, Parveen N, Habeeb MA, Habibullah CM. Journey from hepatocyte transplantation to hepatic stem cells: a novel treatment strategy for liver diseases. Indian J Med Res. 2006; 123(5): 601-14. PMID: 16873904.

3) Stieger B, Peters R, Sidler MA, Meier PJ. Hepatocyte transplantation: potential of hepatocyte progenitor cells and bone marrow derived stem cells. Swiss med wkly. 2006; 136: 552-6. PMID: 17043946.

4) Fausto N, Campbell JS. The role of hepatocytes and oval cells in liver regeneration and repopulation. Mech Dev. 2003; 120(1): 117-30. doi: 10.1016/S0925-4773(02)00338-6. PMID: 12490302.

5) Wang X, Foster M, Al-Dhalimy M, Lagasse E, Finegold M, Grompe M. The origin and liver repopulating capacity of murine oval cells. Proc Natl Acad Sci U S A. 2003; 100(1): 11881-8. doi: 10.1073/pnas.1734199100. PMID: 12902545, PMCID: PMC304102.

6) Laurson J, Selden C, Hodgson HJ. Hepatocyte progenitors in man and in rodents-multiple pathways, multiple candidates. Int J Exp Pathol. 2005; 86(1): 1-18. doi: 10.1111/j.0959-9673.2005.00410.x. PMID: 15676028, PMCID: PMC2517398.

7) Lazaro CA, Rhim JA, Yamada Y, Fausto N. Generation of hepatocytes from oval cell precursors in culture. Cancer Res. 1998; 58: 5514-22. PMID: 9850088.

8) Petersen BE, Bowen WC, Patrene KD, Mars WM, Sullivan AK, Murase N, et al. Bone marrow as a potential source of hepatic oval cells. Science. 1999; 284(5417): 1168-70. doi: 10.1126/science.284.5417.1168. PMID: 10325227.

9) Theise ND, Badve S, Saxena R, Henegariu O, Sell S, Crawford JM, et al. Derivation of hepatocytes from bone marrow cells in mice after radiation-induced myeloablation. Hepatology. 2000; 31(1): 235-40. doi: 10.1002/hep.510310135. PMID: 10613752.

10) Alison MR, Poulsom R, Jeffery R, Dhillon AP, Quaglia A, Jacob J, et al. Hepatocytes from non-hepatic adult stem cells. Nature. 2000; 406(6793): 257. doi: 10.1038/35018642. PMID: 10917519.

11) Vassilopoulos G, Wang PR, Russell DW. Transplanted bone marrow regenerates liver by cell fusion. Nature. 2003; 422(6934): 901-4. doi: 10.1038/nature01539. PMID: 12665833. 
12) Aejaz HM, Khan AA, Parveen N, Baskar S, Mahaboob V, Khaja MN, et al. Stem Cells in Hepatobiliary Diseases. J Stem Cells Regen Med. 2006; 1(1): 2-7. PMID: 24692856 , PMCID: PMC3907966.

13) Sorino HE, Wood RP, Kang DC. Hepatocellular transplantation (HCT) in children with fulminant hepatic failure. Hepatology. 1997; 26: 239.

14) Khan AA, Habeeb A, Parveen N, Naseem B , Babu RP, Capoor AK, et al. Peritoneal transplantation of human fetal hepatocytes for the treatment of acute fatty liver pregnancy. a case report. Trop Gastroenterol. 2004; 25(3): 141-3. PMID: 15682663.

15) Fox IJ, Roy Chowdhary J, Kauffman SS, Goertzen TC, Chowdhury NR, Warkentin PI, et al. Treatment of the Crigler-Najjar syndrome type I with hepatocyte transplantation. N Engl J Med. 1998; 338(20): 1422-6. doi: 10.1056/NEJM199805143382004. PMID: 9580649.

16) Sokal EM, Smets F, Bourgos A, Van Maldergem L, Buts JP, Reding R, et al. Hepatocyte transplantation in a 4-year girl with peroxisomal biogenesis disease: technique, safety and metabolic follow-up. Transplantation. 2003; 76(4): 735-8. doi: 10.1097/01.TP.0000077420.81365.53. PMID: 12973120.

17) Horslen SP, Fox IJ. Hepatocyte transplantation. Transplantation. 2004; 77(10): 1481-6. doi: 10.1097/01.TP.0000113809.53415.C2. PMID: 15239608.

18) Hewitt NJ, Lechón MJG, Houston JB, Hallifax D, Brown HS, Maurel P, et al. Primary hepatocyte: Current understanding of the regulation of metabolic enzymes and transporter proteins, and pharmaceutical practice for the use of hepatocytes in metabolism, enzyme induction, transporter, clearance, and hepatotoxicity studies. Drug Metabolism Reviews. 2007; 39(1): 159-234. doi: 10.1080/03602530601093489. PMID: 17364884.

19) Dhawan A, Mitry RR, Hughes RD, Lehec S, Terry C, Bansal S, et al. Hepatocyte transplantation for inherited factor VII deficiency. Transplantation. 2004; 78(12): 1812-4. doi: 10.1097/01.TP.0000146386.77076.47. PMID: 5614156.

20) Newsome PN, Plevris JN, Nelson LJ, Hayes PC. Animal models of fulminant hepatic failure: a critical evaluation. Liver Transpl. 2000; 6(1): 21-31. doi: 10.1002/lt.500060110. PMID: 10648574.

21) Sudan DL, Shaw Jr BW, Fox IJ, Langnas AN. Long-term follow-up of auxiliary orthotopic liver transplantation for the treatment of fulminant hepatic failure. Surgery. 1997; 122(4): 778-8, 777-8. doi: 10.1016/S0039-6060(97)90086-6. PMID: 9347855.

22) Rozga J. Liver support technology-an update. Xenotransplantation. 2006; 13(1): 380-9. doi: 10.1111/j.1399-3089.2006.00323.x. PMID: 16925661.

23) Lee WM, Squires Jr RH, Nyberg SL, Doo E, Hoofnagle JH. Acute liver failure: summary of a workshop. Hepatology. 2008; 47(4): 1401-15. doi: 10.1002/hep.22177. PMID: 18318440, PMCID: PMC3381946.

24) Mito M, Kusano M, Kawaura Y. Hepatocyte transplantation in man. Transplant Proc. 1992; 24(6): 3052-3. PMID: 1466053.

25) Nagata H, Ito M, Cai J, Edge AS, Platt JL, Fox IJ. Treatment of cirrhosis and liver failure in rats by hepatocyte xenotransplantation. Gastroenterology. 2003; 124(2): 422-31. doi: 10.1053/gast.2003.50065. PMID: 12557148.

26) Nagata H, Ito M, Shirota C, Edge A, McCowan TC, Fox IJ. Route of hepatocyte delivery affects hepatocyte engraftment in the spleen. Transplantation. 2003; 76(4): 732-4. doi: 10.1097/01.TP.0000081560.16039.67. PMID: 12973119.

27) Ott HC, Matthiesen TS, Goh SK, Black LD, Kren SM, Netoff TI, et al. Perfusion decellularized matrix: using nature's platform to engineer a bioartificial heart. Nat Med. 2008; 14(2): 213-21. doi: 10.1038/nm1684. PMID: 18193059.

28) Uygun BE, Soto-Gutierrez A, Yagi H, Izamis ML, Guzzardi MA, Shulman C, et al. Organ re-engineering: development of a transplantable recellularized liver graft using decellularized liver matrix. Nat Med. 2010; 16: 814-20. doi: 10.1038/nm.2170. PMID: 20543851, PMCID: PMC2930603.

29) Nagata H, Nishitai R, Shirota C, Zhang JL, Koch CA, Cai J, et al. Prolonged survival of porcine hepatocytes in cynomolgus monkeys. Gastroenterology. 2007; 132(1): 321-9. doi: 10.1053/j.gastro.2006.10.013. PMID: 17241882.

30) Overturf K, al-Dhalimy M, Ou CN, Finegold M, Grompe M, et al. Serial transplantation reveals the stemcell-like regenerative potential of adult mouse hepatocytes. Am J Pathol. 1997; 151(1): 1273-80. PMID: 9358753, PMCID: PMC1858091.

31) Guo D, Fu T, Nelson JA, Superina RA, Soriano HE. Liver repopulation after cell transplantation in mice treated with retrorsine and carbon tetrachloride. Transplantation. 2002; 73(11): 1818-24. doi: 10.1097/00007890-200206150-00020. PMID: 12085007. 
32) Peters LJ, Withers HR, Cundiff JH, Dicke KA. Radiobiological considerations in the use of total-body irradiation for bone-marrow transplantation. Radiology. 1979; 131(1): 243-7. doi: 10.1148/131.1.243. PMID: 370902.

33) Guha C, Sharma A, Gupta S, Alfieri A, Gorla GR, Gagandeep S, et al. Amelioration of radiation-induced liver damage in partially hepatectomized rats by hepatocyte transplantation. Cancer Res. 1999; 59(23): 5871-4. PMID: 10606225.

34) Dagher I, Nguyen TH, Groyer-Picard MT, Lainas P, Mainot S, Guettier C, et al. Efficient hepatocyte engraftment and long-term transgene expression after reversible portal embolization in nonhuman primates. Hepatology. 2009; 49(3): 950-9. doi: 10.1002/hep.22739. PMID: 19152424.

35) Fox IJ, Roy-Chowdhury J. Hepatocyte transplantation. J Hepatol. 2004; 40: 878-86. doi: 10.1016/j.jhep.2004.04.009. PMID: 15158325.

36) Yamanouchi K, Zhou H, Roy-Chowdhury N, Macaluso F, Liu L, Yamamoto T, et al. Hepatic irradiation augments engraftment of donor cells following hepatocyte transplantation. Hepatology. 2009; 49(1): 25867. doi: 10.1002/hep.22573. PMID: 19003915, PMCID: PMC3416044.

37) Guha C, Yamanouchi K, Jiang J, Wang X, Roy Chowdhury N, Santana A, et al. Feasibility of hepatocyte transplantation-based therapies for primary hyperoxalurias. Am J Nephrol. 2005; 25(2): 161-70. doi: 10.1159/000085408. PMID: 15849463.

38) Mitry RR, Dhawan A, Hughes RD, Bansal S, Lehec S, Terry C, et al. One liver, three recipients: segment IV from split-liver procedures as a source of hepatocytes for cell transplantation. Transplantation. 2004; 77(10): 1614-6. doi: 10.1097/01.TP.0000122224.98318.19. PMID: 15239631.

39) Hughes RD, Mitry RR, Dhawan A, Lehec SC, Girlanda R, Rela M, et al. Isolation of hepatocytes from livers from non-heart-beating donors for cell transplantation. Liver Transpl. 2006; 12(5): 713-7. doi: 10.1002/lt.20732. PMID: 16528714.

40) Meyburg J, Das AM, Hoerster F, Lindner M, Kriegbaum H, Engelmann G, et al. One liver for four children: first clinical series of liver cell transplantation for severe neonatal urea cycle defects. Transplantation. 2009; 87(5): 636-41. doi: 10.1097/TP.0b013e318199936a. PMID: 19295306.

41) Puppi J, Dhawan A. Human hepatocyte transplantation overview. Methods Mol Biol. 2009; 481: 1-16. doi: 10.1007/978-1-59745-201-4-1. PMID: 19096807.

42) Si-Tayeb K, Noto FK, Nagaoka M, Li J, Battle MA, Duris C, et al. Highly efficient generation of human hepatocyte-like cells from induced pluripotent stem cells. Hepatology. 2010; 51(1): 297-305. doi: 10.1002/hep.23354. PMID: 19998274, PMCID: PMC2946078.

43) Yu J, Hu K, Smuga-Otto K, Tian S, Stewart R, Slukvin II, et al. Human induced pluripotent stem cells free of vector and transgene sequences. Science. 2009; 324(5968): 797-801. doi: 10.1126/science.1172482. PMID: 19325077, PMCID: PMC2758053.

44) Platt JL. New directions for organ transplantation. Nature. 1998; 392(6679): 11-7. doi: 10.1038/32023. PMID: 9579856.

45) Gunsalus JR, Brady DA, Coulter SM, Gray BM, Edge AS. Reduction of serum cholesterol in Watanabe rabbits by xenogeneic hepatocellular transplantation. Nat Med. 1997; 3(1): 48-53. doi: 10.1038/nm0197-48. PMID: 8986740.

46) Yamada K, Yazawa K, Shimizu A, Iwanaga T, Hisashi Y, Nuhn M, et al. Marked prolongation of porcine renal xenograft survival in baboons through the use of alpha1, 3-galactosyltransferase gene-knockout donors and the cotransplantation of vascularized thymic tissue. Nat Med. 2005; 11(1): 32-4. doi: 10.1038/nm1 172. PMID: 15619627.

47) Walker CM. Comparative features of hepatitis $C$ virus infection in humans and chimpanzees. Springer Semin Immunopathol. 1997; 19(1): 85-98. doi: 10.1007/BF00945027. PMID: 9266633. 